\title{
What Can Family Physicians Offer Patients With Carpal Tunnel Syndrome Other Than Surgery? A Systematic Review of Nonsurgical Management
}

Felicity Goodyear-Smith, MB, CbB, MGP

Bruce Arroll, MB, ChB, PhD

Department of General Practice \& Primary Health Care, Faculty of Medical \& Health Sciences, The University of Auckland, Auckland, New Zealand

hil

MORE ONLINE www.annfammed.org
Conflict of interest: none reported

\section{CORRESPONDING AUTHOR}

Felicity Goodyear-Smith, MB, ChB, MGP Department of General Practice \& Primary Health Care

Faculty of Medical \& Health Sciences

University of Auckland, Private Bag 92019

Auckland, New Zealand

f.goodyear-smith@auckland.ac.nz

\begin{abstract}
BACKGROUND We undertook a literature review to produce evidence-based recommendations for nonsurgical family physician management of carpal tunnel syndrome (CTS).

METHODS Study design was systematic review of randomized controlled trials (RCTs) on CTS treatment. Data sources were English publications from all relevant databases, hand searches, and guidelines. Outcomes measured were nonsurgical management options for CTS.

RESULTS We assessed 2 systematic reviews, 16 RCTs, and 1 before-and-after study using historical controls. A considerable percentage of CTS resolves spontaneously. There is strong evidence that local corticosteroid injections, and to a lesser extent oral corticosteroids, give short-term relief for CTS sufferers. There is limited evidence to indicate that splinting, laser-acupuncture, yoga, and therapeutic ultrasound may be effective in the short to medium term (up to 6 months). The evidence for nerve and tendon gliding exercises is even more tentative. The evidence does not support the use of nonsteroidal anti-inflammatory drugs, diuretics, pyridoxine (vitamin $\mathrm{B}_{6}$ ), chiropractic treatment, or magnet treatment.
\end{abstract}

CONCLUSIONS For those who are not able to get surgery or for those who do not want surgery, there are some conservative modalities that can be tried. These modalities include ones for which there is good evidence. It would be reasonable to try some of the techniques with less evidence if the better ones are not successful. Reconsideration of surgery must always be kept in mind to avoid permanent nerve damage.

Ann Fam Med 2004;2:267-273. DOI: 10.1370/afm.21

\section{INTRODUCTION}

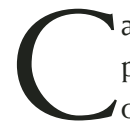
arpal tunnel syndrome (CTS) is the most commonly occurring peripheral nerve compression syndrome, with a $10 \%$ lifetime risk with women affect with women affected more than men by a factor of 3 to $1 .{ }^{2}$ A US study of 1,016 patients at the Mayo Clinic found an incidence (cases per 100,000 person-years) of 99 (crude) overall. The age-adjusted rates were 52 for men, 149 for women, and 105 for both sexes combined. ${ }^{2}$

CTS involves median nerve compression at the level of the wrist. Median nerve entrapment can result in sensory and motor impairment, as well as pain in the hand and or arm. There is no single reference standard for diagnosis of the syndrome, and a combination of symptoms, signs, and tests should be used to characterize the disorder. ${ }^{1}$ Distinction should be made between CTS (a clinical syndrome involving a cluster of symptoms) 
and distal median neuropathy (a structural abnormality with pathophysiological findings on nerve conduction studies). It should be noted that distal median neuropathy can sometimes be asymptomatic; conversely, patients with CTS can occasionally have normal nerve conduction study results.

Although most cases are idiopathic (have no identifiable cause), ${ }^{3}$ CTS is also associated with a number of systemic conditions, including rheumatoid arthritis, hypothyroidism, diabetes mellitus, acromegaly, gout, and pregnancy. ${ }^{1,4}$ Because the carpal tunnel runs between the transverse carpal ligament and the carpal bones, damage to this region can result from a number of compression lesions, including local trauma, overuse of the hand or wrist, or prolonged improper positioning. Occupational causes contribute to the occurrence of CTS. Even though there has been a large increase in the reporting of work-related repetitive strain injuries during the past 2 decades, only about $2 \%$ of these are CTS. ${ }^{5}$

There is strong evidence of a positive association between exposure to a combination of risk factors (such as force and repetition) and CTS. ${ }^{6}$ Evidence is reported of a positive association of CTS and highly repetitive work alone or in combination with other factors and forceful work and with work involving hand and wrist vibration. ${ }^{6,7}$ Epidemiologic surveillance data also consistently indicate that the highest rates of CTS occur with job tasks that have high work demands for intensive manual exertion-for example, in meatpackers, poultry processors, and automobile assembly workers. ${ }^{6}$

Insufficient evidence of a positive association has been found between posture and CTS. ${ }^{6}$ Self-diagnosis of prolonged hand discomfort as CTS is very common, ${ }^{8}$ and keyboard workers who develop hand pain may have CTS wrongly diagnosed. Although the incidence of diagnosed CTS has increased during the past 20 years, ${ }^{2}$ and public attention has focused on excessive keyboard use, ${ }^{9}$ frequent computer use has not yet been established as a cause of CTS. ${ }^{6}$ One survey of employees who were frequent computer users found that their frequency of CTS was similar to that in the general population. ${ }^{10}$

Many patients report spontaneous recovery. Others do not access surgical options because of waiting times and cost of surgery, or they prefer not to embark on surgery. For these patients, short-term nonsurgical management may be desirable. There is, however, a risk of permanent damage to the median nerve, hence, primary care physicians need to consider nonsurgical options with caution.

The aim of our study was to conduct a systematic review of the literature and produce evidence-based recommendations for nonsurgical family physician management of CTS.

\section{METHODS}

The review included randomized controlled studies that assessed the efficacy of nonsurgical treatment of CTS. Non-English papers were excluded because translations were not available. The restriction to English language studies is unlikely to cause any bias, as a recent assessment reported that non-English papers are likely to be of low quality and could introduce bias into a review. ${ }^{11}$

Relevant studies were identified using Cochrane Library and controlled trials register, MEDLINE (1966 to 2002), and EMBASE (1980 to 2002). The review also included international guidelines, computer searches based on key words, hand searching for references from previously retrieved articles and communication with international authors to obtain unpublished material. Figure 1 displays the search summary.

The relevant papers were selected by one author (FG) and critiqued by both authors. The key papers were entered into evidence tables. The quality of their methods was assessed with the PEDro (Physiotherapy Evidence Database) scale, which gives a total score of 10 possible points. ${ }^{12,13}$ The key aspects of quality were whether the studies were randomized, allocation was concealed, reasonable follow-up was achieved, and maintenance of blinding where appropriate. Any disagreements were resolved by discussion. Studies require a score of at least 3 to be included in the analysis.

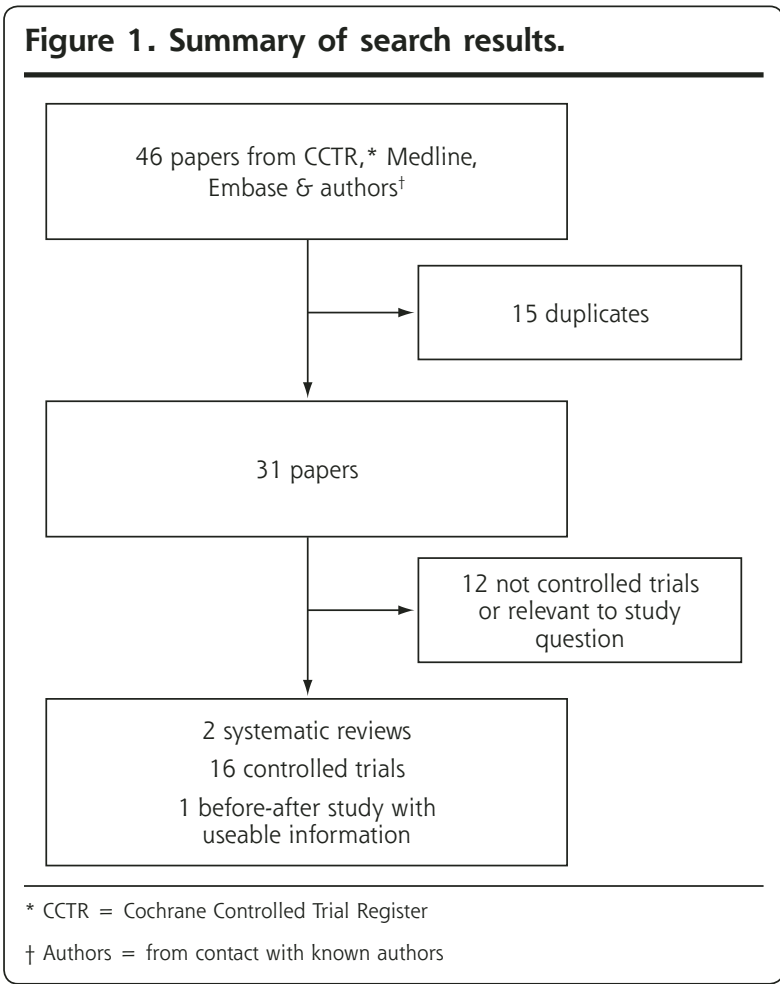


Other more general comments on blinding are shown in Appendix 1, which is available online at http://www.annfammed.org/cgi/content/full/ 2/3/267/DC1. ${ }^{14-30}$ The strength of the evidence was graded using the Scottish Intercollegiate Guidelines Network (SIGN) revised grading system (Appendix 2, which is available online at http: //www.annfammed.org/cgi/content/full/2/3/267/DC1). ${ }^{31}$ SIGN was formed in 1993 to improve the effectiveness and efficiency of clinical patient care by developing evidence-based guidelines prepared by a multiprofessional group.

\section{RESULTS}

The quality of the methods ranged widely, from 3 to 10 (Table 1). ${ }^{14-15 \cdot 27-30}$ There is limited evidence that a significant percentage of cases of idiopathic CTS will resolve without treatment. ${ }^{3,32}$ High response rates to placebo treatments suggest rates of $50 \%$ or more. The small number of studies and the wide range of outcomes made statistical pooling unfeasible.

A Cochrane systematic review found that local steroid injection for CTS significantly improved symptoms for a period up to 1 month after treatment. ${ }^{17,20,24,33}$ This finding has also been confirmed in a more recent randomized controlled trial (RCT). ${ }^{23}$ One 1994 study reported that in cases of mild idiopathic CTS, no significant difference was found between steroid injection and placebo, but $63 \%$ of patients experienced symptomatic improvement irrespective of whether they received steroid injection or placebo. ${ }^{20}$

Two RCTs ${ }^{16,22}$ have found short-term relief of symptoms with the use of oral corticosteroids. ${ }^{3}$ One RCT has found that 10 days of oral corticosteroid is significantly less effective than local steroid injection in achieving symptom relief at 12 weeks. ${ }^{30}$ Table 2 displays the characteristics of effective nonsurgical treatments.

There are no RCTs comparing wrist splinting with no treatment. One RCT suggested that full-time was better

Table 1. Quality Scores of Studies in Systematic Review

\begin{tabular}{|c|c|c|c|c|c|c|c|c|c|c|c|c|}
\hline \multirow[b]{2}{*}{ Author } & \multicolumn{12}{|c|}{ Scores in PEDro Scale* } \\
\hline & 1 & 2 & 3 & 4 & 5 & 6 & 7 & 8 & 9 & 10 & 11 & Total Score Y \\
\hline Aigner \& Fielka, $1998^{14}$ & - & + & $?$ & $?$ & + & $?$ & $?$ & $?$ & $?$ & + & - & 3 \\
\hline Carter et al, $2002^{15}$ & + & + & + & + & + & + & + & - & $?$ & + & + & 8 \\
\hline Chang et al, $1998^{16}$ & + & + & + & + & + & + & + & + & $?$ & + & - & 8 \\
\hline Dammers et al, $1999^{17}$ & + & + & $?$ & + & + & + & + & + & + & + & + & 9 \\
\hline Davis et al, $1998^{18}$ & + & + & - & + & - & - & - & - & + & + & + & 5 \\
\hline Ebenbichler et al, $1998^{19}$ & + & + & $?$ & + & + & + & $?$ & - & + & + & + & 7 \\
\hline Elbaz et al, $1994^{20}$ & - & + & $?$ & + & + & + & + & $?$ & $?$ & + & $?$ & 6 \\
\hline Garfinkel et al, $1998^{21}$ & + & + & + & + & $?$ & - & + & - & - & + & - & 5 \\
\hline Herskovitz et al, $1995^{22}$ & + & + & $?$ & + & + & + & + & - & - & + & - & 6 \\
\hline O'Gradaigh \& Merry, $2000^{23}$ & + & + & $?$ & + & + & $?$ & - & $?$ & $?$ & + & - & 4 \\
\hline Ozdogan E Yazici, $1984^{24}$ & + & + & $?$ & + & + & + & + & - & $?$ & + & + & 7 \\
\hline Oztas et al, $1998^{25}$ & + & + & $?$ & + & + & $?$ & $?$ & $?$ & $?$ & + & + & 5 \\
\hline Spooner et al, $1993^{27}$ & + & + & $?$ & + & + & + & + & + & $?$ & + & + & 8 \\
\hline Stransky et al, $1989^{28}$ & - & + & $?$ & $?$ & + & $?$ & $?$ & + & $?$ & - & - & 3 \\
\hline Walker et al, $2000^{29}$ & + & + & $?$ & + & - & - & - & - & $?$ & + & + & 5 \\
\hline Wong et al, $2001^{30}$ & + & + & + & + & + & + & + & + & + & + & + & 10 \\
\hline \multicolumn{13}{|c|}{ * Column numbers correspond to the following on the PEDro scale: } \\
\hline \multicolumn{13}{|c|}{ 1. Eligibility criteria were specified. } \\
\hline \multicolumn{13}{|c|}{ 2. Subjects were randomly allocated to groups. } \\
\hline \multicolumn{13}{|l|}{ 3. Allocation was concealed. } \\
\hline \multicolumn{13}{|c|}{ 4. Groups were similar at baseline. } \\
\hline \multicolumn{13}{|c|}{ 5. Subjects were blinded. } \\
\hline \multicolumn{13}{|c|}{ 6. Practitioners who administered the intervention were blinded. } \\
\hline \multicolumn{13}{|l|}{ 7. Assessors were blinded. } \\
\hline \multicolumn{13}{|c|}{ 8. Measurements of key outcomes were obtained from $>85 \%$ of subjects. } \\
\hline \multicolumn{13}{|c|}{ 9. Data were analyzed by intention to treat. } \\
\hline \multicolumn{13}{|c|}{ 10. Statistical comparisons between groups were conducted. } \\
\hline \multicolumn{13}{|c|}{ 11. Point measures and measures of variability were provided. } \\
\hline
\end{tabular}




\section{Table 2. Effective Nonsurgical Treatments for Carpal Tunnel Syndrome}

\begin{tabular}{|c|c|c|c|c|c|}
\hline Treatment & Initial Success & Long-Term Success & Evidence & Advantages & Disadvantages \\
\hline $\begin{array}{l}\text { Local corticosteroid } \\
\text { injection }\end{array}$ & $\begin{array}{l}20 / 24(86 \%) \\
\text { responded }\end{array}$ & $\begin{array}{l}\text { Within } 1 \text { year, 50\% } \\
\text { required surgery }\end{array}$ & $\begin{array}{l}\text { Systematic review }{ }^{33} \text {; } \\
4 \text { RCTs }^{17,20,23,24}\end{array}$ & $\begin{array}{l}\text { Effective symptom relief; some } \\
\text { patients may not progress to } \\
\text { surgery }\end{array}$ & $\begin{array}{l}\text { Local steroid affords } \\
\text { only temporary relief }\end{array}$ \\
\hline Oral steroid & $\begin{array}{l}\text { Significant short- } \\
\text { term symptom } \\
\text { reduction }\end{array}$ & $\begin{array}{l}\text { Unknown } \\
\text { Waning of effect over } \\
8 \text { weeks }\end{array}$ & $2 \mathrm{RCTs}^{16,22}$ & $\begin{array}{l}\text { Effective short-term symptom } \\
\text { relief; some patients may not } \\
\text { progress to surgery }\end{array}$ & $\begin{array}{l}\text { Potential adverse } \\
\text { reactions to oral } \\
\text { corticosteroids }\end{array}$ \\
\hline & & & & & $\begin{array}{l}\text { Less effective than } \\
\text { steroid injection }{ }^{30}\end{array}$ \\
\hline
\end{tabular}

Table 3. Possibly Effective Nonsurgical Treatments for Carpal Tunnel Syndrome

\begin{tabular}{|c|c|c|c|c|c|}
\hline Treatment & Initial Success & $\begin{array}{l}\text { Long-Term } \\
\text { Success }\end{array}$ & Evidence & Advantages & Disadvantages \\
\hline Laser-acupuncture & $\begin{array}{l}\text { Reduction in night pain } \\
\text { but not paraesthesia }\end{array}$ & Unknown & 1 poor-quality $\mathrm{RCT}^{14}$ & $\begin{array}{l}\text { Possible preoperative } \\
\text { analgesic agent }\end{array}$ & Poor availability \\
\hline $\begin{array}{l}\text { Nerve and tendon } \\
\text { gliding exercises }\end{array}$ & $\begin{array}{l}\text { No significant difference } \\
\text { for Phalen's or Tinel's } \\
\text { sign, or nerve } \\
\text { conduction studies }\end{array}$ & $\begin{array}{l}\text { Significantly reduced } \\
\text { rates of surgery } \\
\text { NNT }=4\end{array}$ & $\begin{array}{l}\text { Before-and-after } \\
\text { study using } \\
\text { historical } \\
\text { controls }^{26}\end{array}$ & Noninvasive & $\begin{array}{l}\text { Reduced surgical rates } \\
\text { may result from } \\
\text { confounders }\end{array}$ \\
\hline Ultrasound & $\begin{array}{l}\text { One study suggested } \\
\text { improvement in both } \\
\text { symptoms and nerve } \\
\text { conduction studies }{ }^{19} ; \\
\text { other study found no } \\
\text { significant difference }{ }^{25}\end{array}$ & Unknown & $\begin{array}{l}2 \mathrm{RCTs}^{19,25} \\
\text { Conflicting evidence }\end{array}$ & Noninvasive & $\begin{array}{l}\text { Expensive } \\
\text { High dropout rate }\end{array}$ \\
\hline Wrist splinting & $\begin{array}{l}\text { Neutral superior to } 20^{\circ} \\
\text { extension splinting } \\
\text { Full-time use significantly } \\
\text { greater improvement } \\
\text { in nerve conduction } \\
\text { studies but no } \\
\text { difference in symptoms }\end{array}$ & Unknown & $\begin{array}{l}1 \text { systematic review }{ }^{35} \\
\text { plus } 1 \mathrm{RCT}^{19} \\
\text { All studies had } \\
\text { methodological } \\
\text { flaws }\end{array}$ & $\begin{array}{l}\text { No harmful effects } \\
\text { noted }\end{array}$ & Poor compliance \\
\hline Yoga & $\begin{array}{l}\text { Significant improvement } \\
\text { in Phalen's sign, grip } \\
\text { strength, and pain } \\
\text { reduction but not Tinel's } \\
\text { sign, sleep disturbance, } \\
\text { or nerve conduction } \\
\text { studies } \\
\text { Control group had wrist } \\
\text { splinting. }\end{array}$ & Unknown & $\mathrm{RCT}$ (single-blind) ${ }^{21}$ & $\begin{array}{l}\text { Noninvasive } \\
\text { Can be home-based } \\
\text { treatment }\end{array}$ & $\begin{array}{l}\text { No changes in nerve } \\
\text { conduction studies } \\
\text { Involves high level of } \\
\text { patient commitment }\end{array}$ \\
\hline
\end{tabular}

than nighttime splint use. ${ }^{29}$ One prospective study found that neutral angle splints were more effective than those set in extension, because an angle splint decreases the potential for the nerve to be stretched. ${ }^{34} \mathrm{~A}$ systematic review concluded that all splinting studies had serious methodological failings. ${ }^{35} \mathrm{~A}$ more recent RCT comparing splinting with surgery found the latter was more effective than splinting on all outcome symptom measures at 3 months, and by 18 months $41 \%$ of the patients in the splint group had received surgical intervention. ${ }^{36}$

One large RCT found short- to medium-term benefit of ultrasound treatment in mild-to-moderate idiopathic CTS compared with placebo ${ }_{1}^{19}$ and another smaller RCT found no significant difference. ${ }^{25}$ There is very limited evidence that a yoga-based intervention might give some symptom relief in CTS. ${ }^{21} \mathrm{~A}$ small ran- domized, single-blinded study found laser-acupuncture resulted in a significant reduction in night pain compared with placebo laser. ${ }^{14}$ This RCT is the only one available, and only a conference abstract is available in the Cochrane database.

Nerve and tendon gliding exercises are designed to restore and maximize the excursion of the median nerve through the carpal tunnel. ${ }^{26}$ These exercises involve intermittent active wrist and digital flexion and extension exercise. While one before-after study suggested some benefit, ${ }^{26}$ there have been no RCTs to evaluate the effectiveness of these exercises. Table 3 displays the characteristics of possibly effective treatments.

There is no evidence that either nonsteroidal antiinflammatory drugs (NSAIDs) $)^{16,18}$ or diuretics ${ }^{16}$ result in clinical improvement in CTS. Although initial stud- 
ies were promising, ${ }^{37-39}$ recent RCT evidence does not indicate that the use of pyridoxine (vitamin $\mathrm{B}_{6}$ ) gives any clinical improvement over placebo in the treatment of CTS. ${ }^{27,28}$ Because all the studies to date involve small sample sizes, the relationship between pyridoxine deficiency and CTS has not been adequately established.

There is no good evidence that chiropractic treatment gives effective symptom relief. One study found that chiropractic treatment did not give improved benefit when compared with NSAID use. ${ }^{18}$ A double-blind placebo-controlled RCT found the use of a magnet for reducing pain attributed to CTS was no more effective than use of a placebo device. ${ }^{15}$ Table 4 displays the characteristics of probably ineffective treatments.

Comparative details of these individual studies can be found in Appendix 1: Methods, and in Appendix 3: Outcomes (Appendix 1 and Appendix 3 are available online at http://www.annfammed.org/cgi/ content/full/2/3/267/DC1). ${ }^{14-30,33-35}$

\section{DISCUSSION}

Conservative management has a place in the early management of mild to moderate CTS and may reduce the number of patients undergoing surgical intervention. Nonsurgical management also has a place in those waiting for surgery or for those who choose not to have surgery.

There is strong evidence that local corticosteroid injections (level of evidence $1++$ recommendation $\mathrm{A}$ ), and to a lesser extent oral corticosteroids (level of evidence $1+$ recommendation $A$ ), give short-term relief for CTS sufferers. There is conflicting evidence suggesting that therapeutic ultrasound is effective. One study found a benefit and one did not. There is insufficient evidence to evaluate whether yoga, nerve and tendon gliding exercises, or laser-acupuncture are effective modalities (unable to grade).

The evidence on wrist splinting showed that splinting at night was not as effective as full-time splinting day and

\begin{tabular}{|c|c|c|}
\hline Treatment & Evidence & Findings \\
\hline NSAID & $2 \mathrm{RCTS}^{16,18}$ & No significant reduction in symptom measures \\
\hline Diuretic & $1 \mathrm{RCT}^{16}$ & $\begin{array}{l}\text { No significant reduction in symptom measures from } \\
\text { baseline to } 4^{\text {th }} \text { week assessment }\end{array}$ \\
\hline Pyridoxine & $2 \mathrm{RCTs}^{27,28}$ & $\begin{array}{l}\text { Reduced finger swelling and discomfort after } \\
\text { movement but no difference in nocturnal pain, } \\
\text { numbness, Phalen's or Tinel's signs or nerve } \\
\text { conduction studies in one study, and no } \\
\text { significant difference in the other study }\end{array}$ \\
\hline $\begin{array}{l}\text { Chiropractic } \\
\text { treatment }\end{array}$ & $1 \mathrm{RCT}^{18}$ & No significant reduction in symptom measures \\
\hline Magnet therapy & $1 \mathrm{RCT}^{15}$ & No difference in effect between magnet and placebo \\
\hline
\end{tabular}

night (level of evidence 1- recommendation A). Given that many patients have predominantly nocturnal symptoms, however, splinting when in bed is likely to be much more acceptable and tolerated by patients than splinting during the day.

Initial diagnosis of CTS is made on clinical symptoms. Because about 50\% will resolve spontaneously, not all need to be referred for nerve conduction studies or surgical assessment. Patients with mild symptoms should be offered conservative treatment. Surgical referral should be considered in patients with symptoms that are causing persistent sleep disturbance, interfering with their ability to work, or otherwise adversely affecting their lifestyle.

Our review indicates that conservative treatment options are limited. In those cases clearly related to occupational job tasks, such as highly repetitive forceful work or work involving hand and wrist vibration, the patient should be advised to modify the activities or movements that caused the CTS. Steroid injection is the most effective nonsurgical treatment, but it can result in possible complications of nerve injury, scar, infection, allergic dermatitis, hypopigmentation, soft tissue atrophy, and tendon rupture. ${ }^{40}$ Similarly, oral corticosteroids can cause adverse reactions, including nausea, anxiety, acne, menstrual irregularities, insomnia, headaches, and mood swings. More serious adverse reactions include peptic ulcer, steroid psychosis, osteoporosis, and adrenal insufficiency. ${ }^{3}$

While the evidence of the benefits is uncertain, there are no recorded harmful effects of splinting. This low-cost option could warrant an initial trial. Similarly, no harmful effects have been documented through the use of nerve and tendon gliding exercises and yoga, and these modalities might be considered as first-line management in selected cases. Ultrasound involves some expense, and the treatment regimes prescribed are time-consuming for the patient, although there is no evidence that it causes harm. Given the limited and conflicting evidence regarding its effectiveness, its use in conservative management is questionable.

Given the potential harmful effects of NSAIDs (users of NSAIDs have about 3 times the risk of developing serious adverse gastrointestinal events compared with nonusers ${ }^{41}$ ) and diuretics (such as elevated serum uric acid levels provoking attacks of gout in predisposed patients; hypokalemia, and increased blood glucose levels), the rare possibility of pyridoxine excess causing a sensory neuropathy, ${ }^{42}$ and the low-risk but serious adverse outcome of permanent impairment or 
death from chiropractic treament ${ }^{43,44}$ in the absence of evidence showing any benefit, these modalities are not recommended in the nonsurgical treatment of CTS.

In general, the management is surgery for persistent (not resolving after 1 year) or deteriorating (worsening clinically plus or minus deterioration on nerve conduction studies) CTS. There are no RCTs comparing surgery with no treatment. Most patients improve considerably after surgery regardless of whether the release is open or endoscopic and whether there is adjunctive use of internal neurolysis. ${ }^{45}$

Surgery can be a highly effective treatment for CTS, but prediction on its outcome depends on the accuracy of the diagnosis before the surgical intervention and the timing of surgery in regard to the onset of symptoms. Current evidence indicates that earlier intervention leads to better results. ${ }^{46}$ One study showed that patients who had surgery within 3 years of the initial diagnosis were twice as likely to have symptom relief than were those whose surgery was delayed more than 3 years. ${ }^{47}$ Because CTS is usually a progressive disease, patients who have had the condition for a number of years are more likely to have advanced compression and damage to the distal median nerve, making complete symptom resolution and full recovery of hand function less likely. One study indicated that patients with intermittent symptoms of numbness and paresthesias had much better sensory recovery than those who had constant symptoms preoperatively. ${ }^{48}$

Evidence indicates that patients with advanced median nerve damage have a less positive response to surgery. Current surgical thinking, although not supported by current evidence, would suggest that surgical intervention should be considered after symptoms have been present for at least 6 months, but if indicated, surgery should have taken place within 3 years from the initial diagnosis.

Our review has revealed that both injected and oral steroids have a short-term benefit. A number of other therapies are either of poor quality or have contradictory evidence. In general, the quality of the studies was poor and the size of the studies relatively small. Future research in the form of rigorous well-conducted studies of these various therapies (laser acupuncture, nerve and tendon gliding exercises, ultrasound, wrist splinting, and yoga) would be beneficial in establishing the effectiveness or otherwise of these various treatments. There are also a number of studies that showed no benefit (NSAIDs, diuretics, pyridoxine, chiropractic, and magnet treatments), and these therapies should be avoided. For those who are not able to get or do not want surgery, some conservative modalities can be tried that include those that have good evidence of therapeutic effect. It would be reasonable to try techniques with less evidence of therapeutic effect if the better evidenced ones are not successful. Reconsidering surgery must always be kept in mind to avoid permanent nerve damage.

To read or post commentaries in response to this article, see it online at http://www.annfammed.org/cgi/content/full/2/3/267.

Key words: Carpal tunnel syndrome; preoperative care; review literature

Submitted October 2, 2002; submitted, revised, March 20, 2003; accepted April 22, 2003.

Funding support: This study was conducted with the support of the New Zealand Accident Rehabilitation and Compensation Insurance Corporation Healthwise.

Acknowledgments: This study was conducted at the request and with the support of the New Zealand Accident Rehabilitation and Compensation Insurance Corporation (ARCIC) Healthwise. The opinions expressed in this report are those of the authors rather than the medical advisors. They do not necessarily represent those of the ARCIC. We would like to thank our medical advisors for their assistance in this project.

\section{References}

1. Practice parameter for carpal tunnel syndrome [summary statement]. Report of the Quality Standards Subcommittee of the American Academy of Neurology. Neurology. 1993;43:2406-2409.

2. Stevens JC, Sun S, Beard CM, O'Fallon WM, Kurland LT. Carpal tunnel syndrome in Rochester, Minnesota, 1961 to 1980. Neurology. 1988;38:134-138.

3. Marshall S. Carpal tunnel syndrome. Clin Evid. 2001;5:717-728.

4. Spinner RJ, Bachman JW, Amadio PC. The many faces of carpal tunnel syndrome. Mayo Clin Proc. 1989;64:829-836.

5. Mackinnon SE, Novak CB. Repetitive strain in the workplace. J Hand Surg [Am]. 1997;22:2-18.

6. Bernard B. Musculoskeletal Disorders (MSDs) and Workplace Factors: A Critical Review of Epidemiologic Evidence for Work-Related Musculoskeletal Disorders of the Neck, Upper Extremity, and Low Back. Cincinnati: Centers for Disease Control and Prevention National Institute for Occupational Safety and Health; 1997.

7. Tanaka S, Wild DK, Cameron LL, Freund E. Association of occupational and non-occupational risk factors with the prevalence of selfreported carpal tunnel syndrome in a national survey of the working population. Am J Indust Med. 1997;32:550-556.

8. Tanaka S, Wild DK, Seligman PJ, Behrens V, Cameron L, Putz-Anderson $V$. The US prevalence of self-reported carpal tunnel syndrome: 1988 National Health Interview Survey data. Am J Pub Health. 1994;84:1846-1848.

9. Olney RK. Carpal tunnel syndrome: complex issues with a "simple" condition. Neurology. 2001;56:1431-1432.

10. Stevens JC, Witt JC, Smith BE, Weaver AL. The frequency of carpal tunnel syndrome in computer users at a medical facility. Neurology. 2001;56:1568-1570.

11. Egger M, Juni $P$, Bartlett $C$, Holenstein F, Sterne J. How important are comprehensive literature searches and the assessment of trial quality in systematic reviews? Empirical study. Health Technol Assess. 2003;7:68.

12. Verhagen $A$, de Vet $H$, de Bie $R$, et al. The Delphi list: a criteria list for quality assessment of randomized clinical trials for conducting systematic reviews developed by Delphi consensus. J Clin Epidem. $1998 ; 51: 1235-1241$. 
13. Herbert RD, Gabriel M. Effects of stretching before and after exercising on muscle soreness and risk of injury: systematic review. BMJ. 2002;325:468.

14. Aigner N, Fialka C. Results of laser-acupuncture in carpal tunnel syndrome - a prospective, randomised and blinded study (presented at the 5th Annual Symposium on Complementary Healthcare, 10-12 December 1998, Exeter). FACT: Focus on Alternative and Complementary Therapies 1988;4:180.

15. Carter R, Hall T, Aspy CB, Mold J. The effectiveness of magnet therapy for treatment of wrist pain attributed to carpal tunnel syndrome. J Fam Pract. 2002;51:38-40.

16. Chang MH, Chiang HT, Lee SS, Ger LP, Lo YK. Oral drug of choice in carpal tunnel syndrome. Neurology. 1998;51:390-393.20.

17. Dammers JW, Veering MM, Vermeulen M. Injection with methylprednisolone proximal to the carpal tunnel: randomised double blind trial. BMJ. 1999;319:884-886

18. Davis PT, Hulbert JR, Kassak KM, Meyer JJ. Comparative efficacy of conservative medical and chiropractic treatments for carpal tunnel syndrome: a randomized clinical trail. J Manipulative Physiol Ther. 1998;21:317-326.

19. Ebenbichler GR, Resch $K L$, Nicolakis $P$, et al. Ultrasound treatment for treating the carpal tunnel syndrome: randomised "sham" controlled trial. BMJ. 1998;316:731-735.

20. Elbaz A, Gagnon S, Beaumont P, et al. Carpal tunnel syndrome: a double blind study of the effect of steroid injection. J Bone Joint Surg. 1994;76-B Suppl:22.

21. Garfinkel MS, Singhal A, Katz WA, Allan DA, Reshetar R, Schumacher HR Jr. Yoga-based intervention for carpal tunnel syndrome: a randomized trial. JAMA. 1998;280:1601-1603.

22. Herskovitz S, Berger AR, Lipton RB. Low-dose, short-term oral prednisone in the treatment of carpal tunnel syndrome. Neurology. 1995;45:1923-1925.

23. O'Gradaigh D, Merry P. Corticosteroid injection for the treatment of carpal tunnel syndrome. Ann Rheum Dis. 2000;59:918-919.

24. Ozdogan $H$, Yazici $H$. The efficacy of local steroid injections in idiopathic carpal tunnel syndrome: a double-blind study. Brit J Rheumatol. $1984 ; 23: 272-275$.

25. Oztas O, Turan B, Bora I, Karakaya MK. Ultrasound therapy effect in carpal tunnel syndrome. Arch Phys Med Rehab.1998;79:1540-1544.

26. Rozmaryn LM, Dovelle S, Rothman ER, Gorman K, Olvey KM, Bartko $\mathrm{JJ}$. Nerve and tendon gliding exercises and the conservative management of carpal tunnel syndrome. J Hand Ther. 1998;11:171-179.

27. Spooner GR, Desai HB, Angel JF, Reeder BA, Donat JR. Using pyridoxine to treat carpal tunnel syndrome. Randomized control trial. Can Fam Phys. 1993;39:2122-2127.

28. Stransky M, Rubin A, Lava NS, Lazaro RP. Treatment of carpal tunnel syndrome with vitamin B6: a double-blind study. South Med J. 1989;82:841-842.

29. Walker WC, Metzler M, Cifu DX, Swartz Z. Neutral wrist splinting in carpal tunnel syndrome: a comparison of night-only versus full-time wear instructions. Arch Phys Med Rehab. 2000;81:424-429.

30. Wong SM, Hui AC, Tang A, et al. Local vs systemic corticosteroids in the treatment of carpal tunnel syndrome. Neurology. 2001;56:1565-1567.
31. Scottish Intercollegiate Guidelines Network (SIGN) revised grading system for recommendations in evidence-based clinical guidelines. Available at: http://www.sign.ac.uk.

32. Padua L, Padua R, Aprile I, Pasqualetti P, Tonali P, for the Italian CTSSGCts. Multiperspective follow-up of untreated carpal tunnel syndrome: a multicenter study. Neurology. 2001;56:1459-1466.

33. Marshall S, Tardif G, Ashworth N. Local corticosteroid injection for carpal tunnel syndrome. Cochrane Database Syst Rev. 2002;CD001544.

34. Burke DT, Burke MM, Stewart GW, Cambre A. Splinting for carpal tunnel syndrome: in search of the optimal angle. Arch Phys Med Rehab. 1994;75:1241-1244.

35. Feuerstein M, Burrell LM, Miller VI, Lincoln A, Huang GD, Berger R. Clinical management of carpal tunnel syndrome: a 12-year review of outcomes. Am J Indust Med. 1999;35:232-245.

36. Gerritsen A, de Vet H, Scholten R, Bertelsmann F, de Krom M, Bouter L. Splinting vs surgery in the treatment of carpal tunnel syndrome a randomized controlled trial. JAMA. 2002;288:1245-1251.

37. Wolaniuk A, Vadhanavikit S, Folkers K. Electromyographic data differentiate patients with the carpal tunnel syndrome when double blindly treated with pyridoxine and placebo. Res Commun Chem Pathol Pharmacol. 1983;41:501-511.

38. Ellis J, Folkers K, Watanabe T, et al. Clinical results of a cross-over treatment with pyridoxine and placebo of the carpal tunnel syndrome. Am J Clin Nutr. 1979;32:2040-2046.

39. Ellis JM, Folkers K, Levy M, et al. Response of vitamin B-6 deficiency and the carpal tunnel syndrome to pyridoxine. Proc Natl Acad Sci USA. 1982;79:7494-7498.

40. American Society of Plastic Surgeons (ASPS) Guidelines Committee. Carpal Tunnel Syndrome: Clinical Practice Guideline. Arlington: American Society of Plastic and Reconstructive Surgeons (ASPRS); 1998.

41. Gabriel SE, Jaakkimainen L, Bombardier C. Risk for serious gastrointestinal complications related to use of nonsteroidal anti-inflammatory drugs. A meta-analysis. Ann Intern Med. 1991;115:787-796.

42. Bassler KH. Use and abuse of high dosages of vitamin B6. Intl J Vit Nutr Res - Suppl. 1989;30:120-126.

43. Hurwitz EL, Aker PD, Adams AH, Meeker WC, Shekelle PG. Manipu lation and mobilization of the cervical spine. A systematic review of the literature. Spine. 1996;21:1746-1759; discussion 59-60.

44. Rosner AL. Chiropractic: more good than harm or vice versa? J Manipulative Physiol Ther. 1999;22:250-253.

45. Kluge W, Simpson RG, Nicol AC. Late complications after open carpal tunnel decompression. J Hand Surg. 1996;21:205-207.

46. Light T. American Society for Surgery of the Hand: Hand surgery Update 2. Rosement, III: American Academy of Orthopedic Surgeons; 1999.

47. DeStefano F, Nordstrom DL, Vierkant RA. Long-term symptom outcomes of carpal tunnel syndrome and its treatment. J Hand Surg [Am]. $1997 ; 22: 200-210$

48. Rosen B, Lundborg G, Abrahamsson SO, Hagberg L, Rosen I. Sensory function after median nerve decompression in carpal tunnel syndrome. Preoperative vs postoperative findings. J Hand Surg. 1997;22: 602-606. 